Possible role of cortisol

\section{and dehydroepiandrosterone in}

\section{human development and psychopathology ${ }^{\dagger}$}

\author{
I. M. GOODYER, R. J. PARK, C. M. NETHERTON and J. HERBERT
}

Cortisol hypersecretion has consistently been detected in a proportion of cases of major depressive disorder (MDD), mostly in adults, and the increased resistance to the suppressive feedback actions of the synthetic glucocorticoid dexamethasone is a well-recognised association, although neither is specific for MDD. More recently, it has become apparent that enduring alterations in hormones (particularly those from the adrenal cortex) might have more widespread implications for general psychological function, particularly in children exposed to adverse social experiences in early childhood (Gunnar, 1998). This paper reviews new information on three areas of behavioural endocrinology: the developmental changes in adrenal cortical hormones, specifically cortisol and dehydroepiandrosterone (DHEA), in early infancy and childhood; the possible causal role of these hormones in the onset as well as the course of psychopathology with particular reference to MDD; and the action of these steroids in the brain. First, however, we discuss both practical and theoretical aspects of steroid hormone sampling, since all conclusions on their role in normal and abnormal behaviour depend critically on the techniques used to assess them.

\section{MEASUREMENT OF CIRCULATING ADRENAL STEROIDS}

In contrast to the use of indwelling cannulae to obtain blood, or 24-hour urine collections, salivary sampling allows repeated measurements of large populations. Salivary levels correlate highly with serum levels $(r=0.6-0.9)$, and the latter also correlate highly with levels in the ventricular cerebrospinal fluid (CSF) $(r=0.8)$ (Guazzo et al, 1996). Cortisol and DHEA in the saliva may thus reflect levels in the CSF (and hence exposure of the brain to these steroids). Cortisol levels in the saliva (and in the CSF) are about $5 \%$ of those in the serum (Goodyer et al, 1996), reflecting the 'free' (unbound to plasma protein) fraction (see below). Cortisol is secreted in a pulsatile fashion and this is reflected in the saliva with a time lag of about 15 minutes (Kirschbaum \& Hellhammer, 1994).

The principle of salivary collection is to persuade children to spit into sterile containers having previously rinsed out their mouths with water and nothing else. Samples from infants are often actively obtained by swabbing the mouth and squeezing the contents via a syringe into the container. Stimulation of saliva secretion using citric acid crystal, lemon juice or similar is popular but is probably best avoided; these techniques may give inflated salivary levels, as citric acid changes the $\mathrm{pH}$ and hence the characteristics of the assay (Schwartz et al, 1998). It is also essential that the assays used to measure these steroids are sensitive and specific enough to detect the very low levels present in saliva.

Cortisol shows marked reactivity to the environment, which is reflected in the amplitude of the diurnal rhythm: in the saliva of 12 - to 18 -year-olds, this variation is about 10 -fold from $08.00 \mathrm{~h}$ to $20.00 \mathrm{~h}$. In a study of 234 adolescents the mean ratio of salivary cortisol concentrations at $08.00 \mathrm{~h}$ and $20.00 \mathrm{~h}$ was 12.76 (coefficient of variation $66.8 \%$ ) (Goodyer et al, 2000b). It is therefore important to take enough samples over a 24-hour period to define accurately the diurnal pattern of this steroid. Current findings suggest that fewer than four samples spread over 24 hours are unlikely to provide a reliable index of rhythm, and fewer than 4 days of sampling is unlikely to give a valid reflection of mean values. More studies need to be carried out with adequate numbers of subjects, with and without mental disorder, across the age range to define the precise parameters of sampling requirements. Cortisol is produced in reaction to 'stressful' events, so precautions should be taken to ensure that subjects are in a 'basal' state, unless the response to stress or demand is an intended feature of the study (e.g. during a behavioural challenge task).

A further consideration is how the data should be treated. A number of derivations can be obtained which can affect the sampling procedure. For example, it is possible to derive mean group values or 
characterise individual differences by taking peak levels (e.g. greater than the 80th percentile) as an index of higher corticoid activity. The precise selection of measurement is necessarily related to the question being investigated. Few studies to date have adequately considered a prior $i$ these critical quantitative issues.

There are also reports on the use of dexamethasone suppression as an index of cortisol activity in childhood and adolescence (Dahl et al, 1992), based on a much larger adult literature (Plotsky et al, 1998). Dexamethasone suppression is an index of feedback sensitivity, not hypersecretion, and compared with cortisol levels has proved a less consistent index of hypothalamic-pituitary-adrenal (HPA) dysregulation in young people with psychopathology. Pharmacological challenge procedures use drugs (e.g. fenfluramine) to probe the HPA axis or neural systems (e.g. serotonin) that impinge upon it (Park et al, 1996; Cowen, 1998). These techniques provide valuable information on such systems but not on the relations between levels of adrenal steroids, development and psychopathology.

For DHEA, a second major adrenal steroid, the picture is somewhat different. This steroid is also present in the saliva (and CSF) at about $5 \%$ of plasma levels, but there is no known plasma binding protein for DHEA, so the source of this relation remains obscure. The diurnal rhythm in saliva $(08.00 \mathrm{~h}$ to $20.00 \mathrm{~h}$ ) is also much less than for cortisol (about twofold). In our sample of adolescents the mean ratio of salivary DHEA concentrations at $08.00 \mathrm{~h}$ and $20.00 \mathrm{~h}$ was 2.07 (coefficient of variation $33.8 \%$ ). Levels seem to be reduced under conditions of 'demand' such as physical illness.

The cortisol/DHEA ratio thus changes during the day from about 5-7 in the morning $(08.00 \mathrm{~h})$ to about 2 at $20.00 \mathrm{~h}$. This ratio may be interesting in the light of interactions between the two steroids (see below). A proposed minimum standard protocol for studies of young people is shown in the Appendix.

\section{CORTISOL \\ AND DHEA DURING HUMAN DEVELOPMENT}

At birth the human HPA axis system is highly labile and responsive to stimulation, though the diurnal rhythm typical of the adult is lacking. Minor events such as undressing, weighing and measuring will elicit significant elevations of cortisol levels in the newborn (Gunnar et al, 1996a). Mode of birth may represent the first external life event to exert an effect on the HPA axis. Cortisol reactivity to inoculation is significantly higher in 8-week-old infants who have undergone assisted delivery (forceps or ventouse), compared with normal or Caesarean section deliveries (Taylor et al, 2000). This suggests that an early life event may influence subsequent cortisol reactivity in humans, as in experimental animals (Vazquez, 1998). In the latter, early adverse events such as separation from the mother can have long-lasting effects on glucocorticoid reactivity in adult life (e.g. Anisman et al, 1998). A direct test of this hypothesis has not yet been reported in a longitudinal study of human infants.

Gunnar and colleagues have described interesting developmental changes in the reactivity of the adrenocortical system. A 'bio-behavioural shift' in infant functioning occurs during the first 3 months; the cortisol diurnal rhythm becomes apparent and there is a decrease in responsiveness of the adrenal cortex to circulating adrenocorticotrophic hormone (ACTH). A second shift occurs between 3 months and 12 months of life, characterised by another reduction in cortisol reactivity to non-specific general stressors (Gunnar et al, 1996b). By the second year of life events such as physical examination and inoculation fail to elicit significant increases in cortisol level for the average infant. This buffering of the adrenocortical response to stress is more likely in securely than insecurely attached human infants (Lewis \& Ramsay, 1995; Gunnar, 1998).

There is no direct evidence indicating that cortisol levels influence the development and functioning of the brain in children, but several studies are suggestive. For example, a negative correlation has been reported between the late positive component of event-related potentials in 12-month-old human infants presented with visual stimuli, and basal salivary cortisol concentrations. This is thought to reflect a dampening effect of cortisol on hippocampal activity (Gunnar \& Nelson, 1994). There is also a positive association between values of day-to-day cortisol levels in the top 70th percentile of the normal range and poorer 'effortful' control or self-regulatory behaviour (Gunnar et al, 1997). The sample sizes are small and the inter-individual variations can be large, but the implications are that in human infancy the developing brain may be susceptible to modulating effects of high cortisol levels.

Dehydroepiandrosterone shows a very different developmental history. Unlike cortisol, concentrations of DHEA and its sulphate DHEA(S) vary with age (Kroboth et al, 1999). Dehydroepiandrosterone is made by the placenta, so the foetus is exposed to its action. Concentrations decline from the first few months of life until 5 years of age and then rise rapidly from age 7 years in girls and around 9 years in boys (this is called adrenarche), until levels reach their peak between at age 2030 years. Adrenarche is separable from puberty, since gonadotrophins and oestrogen have no effect on DHEA levels and the two events are not linked across time. After age 20-30 years, levels begin to decline in both sexes. By the age of 70-80 years levels are approximately $10-20 \%$ of those in a 20-year-old (Labrie et al, 1997). Little is known about the developmental relations between DHEA(S) and behaviour. Levels of DHEA(S) have not been measured in developmental studies of infants and children. Whether DHEA(S) exerts effects together with or independently of cortisol on normal mental function is not known.

\section{CORTISOL, DHEA AND DEVELOPMENTAL PSYCHOPATHOLOGY}

Research on the functional effects of adrenal steroids in children and adolescents is complicated by developmental changes in cognitive ability and hormonal milieu.

\section{Major depressive disorder \\ Cortisol}

Studies using single blood sampling have failed to show consistent differences in cortisol levels between children with depression and controls (Birmaher et al, 1992, 1996). Subsequent study designs have used multiple non-invasive salivary sampling more closely conforming to the criteria shown in the Appendix. These provided evidence that evening cortisol hypersecretion was found in about $24 \%$ of school-aged children and adolescents with current MDD (Herbert et al, 1996; Goodyer et al, 1997a). This was specifically associated with comorbid dysthymia indicating an association between chronic depressive 
syndromes and cortisol dynamics. A similar proposition followed a longitudinal study of adolescents with recurrent depression (Rao et al, 1996).

\section{DHEA}

Only one study has reported salivary DHEA levels in young patients with current MDD. Hyposecretion of DHEA was significantly associated with MDD, with $31 \%$ of patients with depression aged 8-16 years showing levels below the 20th centile of control subjects (equivalent to less than $0.7 \mathrm{nmol} / \mathrm{l}$ ) (Goodyer et al, 1996). This was not a function of age, nor was it associated with any comorbid syndrome at presentation. Low DHEA levels may occur in a different sub-population of MDD (i.e. those without preceding dysthymia) to those with high cortisol levels. It may be that relatively acute anxious depressive syndromes are less likely to show either cortisol or DHEA abnormalities at presentation.

\section{Cortisol/DHEA ratio}

The (molar) cortisol/DHEA ratio may thus be an important measure of the relative activity of the two steroids; normal levels of cortisol associated with low levels of circulating DHEA may represent an unopposed deleterious risk to the brain (Herbert, 1997). 'Endocrine risk' would incorporate a common population of subjects with depression with two hormonal profiles: higher cortisol levels with normal DHEA, and normal cortisol levels with lower DHEA, leading to the same functional outcome. A higher evening cortisol/ DHEA ratio at entry in subjects with MDD has been shown to be a better predictor of persistent major depression in the short term (i.e. still meeting diagnostic criteria at 36 weeks after presentation) (Goodyer et al, 1997b). This suggests an integrative role for these two adrenal steroids in abnormal psychological processes that maintain or lead to further disturbed interpersonal relationships in already depressed patients.

\section{Adrenal steroids}

\section{and onset of depression}

If individual differences in adrenal steroids are implicated in the onset of psychopathology, then they should be detectable before the onset of episodic disorders such as major depression. Indeed, there is an association between cortisol and DHEA levels and subsequent negative mood (Susman et al, 1991; Brooks-Gunn et al, 1995). A prospective investigation in well adolescents at high risk of psychopathology found significant associations between one or more daily morning peak levels (greater than the 80th percentile of the mean) for cortisol and subsequent MDD in high-risk subjects (Goodyer et al, 2000a,b). There were also associations between evening DHEA peaks and subsequent MDD. These endocrine indices predict MDD independently of recent life events, long-term difficulties or level of premorbid depressive symptoms (Goodyer et al, 2000a,b). These antecedent features of circulating cortisol and DHEA may arise from more distal environmental and/or genetic origins. It remains to be determined whether or not these premorbid psychoendocrine characteristics are entirely specific for MDD.

\section{Gender differences in cortisol and DHEA levels}

A striking feature of a recent community study was the gender difference in levels of cortisol as well as DHEA, independent of age or level and type of environmental risk (Goodyer et al, 2000a). Morning levels of cortisol in the saliva of normal post-pubertal (Tanner stage 2 or more) adolescent girls are about $20 \%$ higher than in an age-matched sample of normal boys, but this is not found in prepubertal children (further details available from the author upon request). Another large community study has reported cross-sectional associations between increased rates of depressive diagnoses in adolescent girls and rising levels of testosterone and oestrogen in mid to late puberty, unrelated to psychosocial factors or body morphology (Angold et al, 1999). Other findings in adolescent girls also support a link between depressed affect and rising or changing levels of oestrogen (Buchanan et al, 1992). However, oestrogens are also positively correlated with good affect and explicit declarative memory (McEwen \& Alves, 1999), making the nature of the relationship between clinical depression and oestrogen somewhat confusing. There appear to be complex and developmentally sensitive interactions between cortisol, DHEA and gonadal steroids that require further elucidation before we can determine the exact nature of the endocrine risk for psychopathology in each gender.

\section{Disorders of behaviour and conduct}

Studies of currently diagnosed disruptive behaviour disorders have reported lower basal levels of cortisol compared with controls (Moss et al, 1995; McBurnett et al, 2000). Reduced cortisol responsivity following a frustration and provocation task have also been noted (van Goozen et $a l, 1998 a, b, c)$. Hyporesponsivity was confined to the conduct disorder group without comorbid anxiety, suggesting distinctive differences in HPA axis function in subtypes of disruptive behaviour disorders (van Goozen et al, 1998a,b, 2000).

Plasma DHEAS levels were higher in those with disruptive behaviour disorders and were positively correlated with the intensity of aggression (van Goozen et al, 1998c). These findings are in marked distinction to those in children and adolescents with depression, and provide further evidence that HPA axis activity varies with the type of psychopathology being investigated.

\section{Child maltreatment}

Child maltreatment is among the most severe and undesirable forms of life event that can occur during early development (Kaplan et al, 1999). Maltreated children are at significant risk for psychopathology in general and emotional disorders in particular. The intervening processes remain unclear, but these types of highly undesirable life experiences may exert a potentially chronic adverse effect on HPA axis function (Kaufman et al, 1997). For example, both urinary catecholamine and free cortisol concentrations showed positive correlations with duration of the trauma and severity of symptoms in maltreated prepubertal children who subsequently met criteria for post-traumatic stress disorder (PTSD) (De Bellis et al, 1999). It is not clear whether hypersecretion is a consequence of maltreatment per se or is related to subsequent emotional psychopathology.

Elevated ACTH and cortisol levels appear to be specifically associated with maltreated subjects who are currently depressed and suffering from other adverse life events and difficulties (Kaufman et al, 1997).

\section{NEUROPSYCHOLOGICAL PROCESSES AND ADRENAL STEROIDS}

\section{Cognitive performance}

Higher cortisol reactivity in young children following a parent-child conflict task may contribute to subsequent internalising 
symptoms over a 6-month period, suggesting effects on general cognitive and emotional performance that might have implications for later psychopathology (Granger et al, 1996). A specific decrease in performance on tests of long-term verbal memory has also been reported in children receiving higher-dose corticosteroids as treatment for asthma (Bender et al, 1988). In adults, reversible cognitive disturbances (e.g. impairments in declarative memory) have also been associated with exposure to either exogenous or endogenous corticosteroids (Keenan et al, 1996; Newcomer et al, 1999). It has been suggested that the neuropsychological impairments seen in adults with depression may occur as a result of the concomitant hypercortisolaemia (McAllister-Williams et al, 1998). The evidence supports the notion that high circulating levels of cortisol are correlated with impaired psychological performance from childhood through to adult life.

\section{Episodic memory and psychopathology}

High levels of cortisol are particularly damaging to the hippocampus (Lupien et al, 1998), an area of the brain that is important for event (episodic) memory. Episodic memory includes context-rich memories relating to the self, known as 'autobiographical' memory, the neural basis of which is closely associated with the hippocampus (Mishkin et al, 1997). Deficits in autobiographical memory retrieval predict persistence of major depressive disorder in adults (Brittlebank et al, 1993). The ontogeny of these types of memories are not known, although autobiographical memories may arise during infancy (Harley \& Reese, 1999), with adult-type memory function present by the age of 8 years (Gathercole, 1998). Early adverse experiences, such as child maltreatment or maternal deprivation, may have undesirable consequences for memory development (Lynch \& Cicchetti, 1998; Pollak et al, 1998), but whether these events operate through effects on brain as a consequence of changes in adrenal steroid function is unclear.

\section{ADRENAL STEROIDS AND THE BRAIN}

\section{Cortisol}

The blood of most species (including humans) contains corticoid-binding globulin (CBG) that binds cortisol with relatively high affinity $\left(K_{\mathrm{D}}\right.$ c. $\left.20 \mathrm{nmol} / \mathrm{l}\right)$, although with limited capacity (Westphal, 1970). Serum albumin also binds corticoids, but with much lower affinity (although with greater capacity). Under basal conditions, about $5 \%$ of total cortisol is in the free form. This is the amount that can pass across the blood-brain barrier or into the saliva. As blood levels begin to increase and as the binding capacity of CBG is exceeded, any additional cortisol will stay in the free condition, so that the amounts passing into the brain rapidly and disproportionately increase (Herbert et al, 1982).

Once within the brain, cortisol interacts with type I and type II intracellular receptors. Type I receptors, also referred to as mineralocorticoid receptors (MRs), demonstrate a high affinity for glucocorticoids (about $0.5 \mathrm{nmol} / \mathrm{l}$ ) while type II or glucocorticoid receptors (GRs) have a 10 -fold lower affinity for glucocorticoids (about $5 \mathrm{nmol} / \mathrm{l}$ ) (Evans \& Arriza, 1989). Once bound to corticoids, MRs and GRs act as ligand-activated transcriptional regulating factors on other (downstream) genes. A large number of such genes have glucocorticoid regulatory elements (GREs) in their promoter regions.

Glucocorticoid receptors are expressed in parts of various brain regions such as the cerebral cortex, hippocampal formation, amygdala, thalamus and hypothalamus. Mineralocorticoid receptors are also expressed in the limbic system and the hypothalamus, but in general their distribution is less extensive than that of GRs (Evans \& Arriza, 1989). As corticoid levels increase, therefore, different populations of receptors will be activated. At lower ('basal') levels, MRs will be preferentially occupied; as brain levels increase (as during the morning peak, or during 'demand') progressively greater numbers of GR will be activated. The MR/GR occupancy ratio will therefore change during the day, and in those exposed to higher levels of cortisol (for whatever reason). In addition to these 'classical' effects, it should be noted that steroids may have other actions on neurons, including modulating membrane-bound receptors (see below).

\section{DHEA}

Much less is known about the action of DHEA on the brain. This compound and its sulphate DHEA(S) are known as neurosteroids because they can be synthesised de novo in the central nervous system (Baulieu, 1998). It seems likely that the blood is the major source of DHEA(S) in the brain of humans, but whether or not the adult brain can make DHEA is still debated.

High DHEA(S) levels are characteristic of primates (rats have very little DHEA); DHEA is secreted synchronously with cortisol in response to CRH and ACTH (Rosenfeld et al, 1971, 1975). However, it is clear that DHEA levels are, in part, regulated independently of cortisol (Ohashi $e t$ al, 1986); the increase in DHEA observed at adrenarche is not mirrored by cortisol, and dissociation between cortisol and DHEA secretion is also seen in disease (Lephart et al, 1987; Anker et al, 1997).

Within the brain, current evidence suggests that DHEA(S) acts on membranebound receptors and is a gamma-aminobutyric acid type $A\left(\mathrm{GABA}_{\mathrm{A}}\right)$ antagonist. These steroids also potentiate the actions of glutamate (or its agonists), enhancing depolarisation and calcium ion entry (Irwin et al, 1992). However, these neuroactive steroids can also alter gene expression in the brain, a second (and more classical) mechanism of action.

In addition, DHEA(S) can act as an antiglucocorticoid. For example, it antagonises the immunosuppressant and lympholytic actions of cortisol (Blauer et al, 1991). There are thus complex and important associations between brain and peripheral structures resulting in the hippocampalhypothalamic-pituitary-adrenal axis which is shown in Fig. 1.

\section{Corticoids and neurotoxicity}

High levels of corticoids can both induce brain damage and accentuate neurotoxic processes (Sapolsky, 1996). Prolonged corticosterone administration to rats increases the age-related rate at which pyramidal neurons in the hippocampus are lost and induces atrophy of apical dendrites (Magarinos \& McEwen, 1995). Chronic social stress does likewise. Neonatal handling - which reduces subsequent stress responses - delays hippocampal degeneration (Meaney et al, 1989). Corticoids also potentiate neurodegeneration induced by such agents as anoxia, glutamate analogues such as kainic acid or cholinergic agents (Hortnagl et al, 1993).

The hippocampus has one extraordinary feature. Active neurogenesis occurs in the dentate gyrus well into adult life (Altman \& Das, 1965), not only in rats but also in 


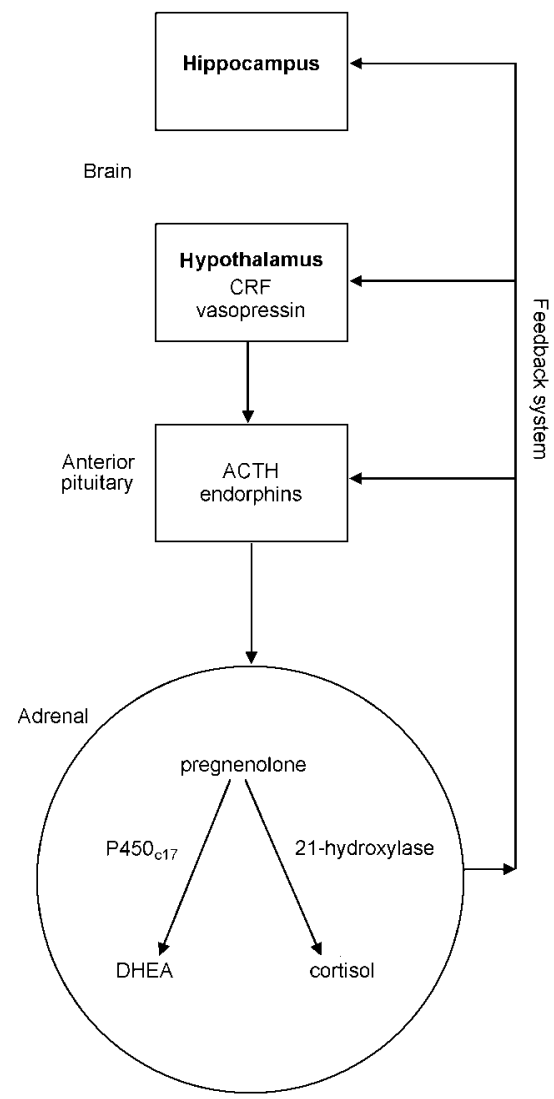

Fig. I The hippocampal-hypothalamicpituitary-adrenal axis; ACTH, adrenocorticotrophic hormone; CRF, corticotrophin releasing factor; DHEA, dehydroepiandrosterone.

monkeys and humans (Eriksson et al, 1998). Furthermore, this process seems to be modulated both by NMDA ( $N$-methyl-Daspartate) receptors and glucocorticoids (Cameron et al, 1998). Persistently higher cortisol levels, from whatever cause, might endanger the functional integrity of the brain and hence increase the probability of cognitive dysfunction and subsequent psychopathology. The developmental origins of these risks remain unclear but early environmental adversities are one set of candidates.

\section{DHEA and neuroprotection}

The hippocampus may be protected by DHEA(S) from the neurotoxic effects of both glutamate analogues and corticoids (Mao \& Barger, 1998). The 'immediateearly' gene c-Jun has been implicated in the response of neurons to injury as part of either degenerative and restorative processes. Recently SAPK/JNK (stress activated protein kinase/c-Jun $\mathrm{N}$-terminal kinase) has been reported to phosphorylate
c-Jun in striatal neuronal cultures following glutamate treatment (Schwarzschild et al, 1997). The activation of SAPK3 by corticosterone was attenuated by DHEA (Kimonides et al, 1999). Overall the experimental evidence, although still preliminary, suggests a combined role for cortisol and DHEA in neurotoxic processes in the brain.

\section{Genes and corticoids}

Although genetic factors may influence levels of both cortisol and DHEA(S) (Meikle et al, 1988) and control human circadian rhythmicity (Linkowski et al, 1993), nothing is known of potential genetic contributions to the features of cortisol or DHEA secretion or their responses to environmental demand during childhood, nor whether the associations between adrenal steroids and the onset and outcome of MDD are genetically mediated.

Adrenal steroids also alter the expression of serotonin $(5-\mathrm{HT})$ receptors, for example $5-\mathrm{HT}_{1 \mathrm{~A}}, 5-\mathrm{HT}_{2 \mathrm{C}}$ (Holmes et al, 1995), although whether there are genetic controls on this action has not been determined. The $5-\mathrm{HT}_{1 \mathrm{~A}}$ receptors are both autoreceptors and post-synaptic receptors, so changes in their activity may have complex effects on serotonin. Serotonin receptor $5-\mathrm{HT}_{1 \mathrm{~A}}$ knockout mice show heightened anxiety and increased 'behavioural despair' (an antidepressant-sensitive test) (Ramboz et al, 1998). In humans, higher levels of morning cortisol in those at risk of MDD may contribute to this downregulation of $5-\mathrm{HT}_{1 \mathrm{~A}}$ receptors, thereby reducing the efficacy of released serotonin and increasing the liability to affective symptoms (Graeff et al, 1996).

\section{Stress, corticoids and gene expression in the brain}

Experimental stress in rodents induces the neural expression of a range of 'immediate-early' genes, such as $c$-OFS, OFS- $B, e g r-1$, and this pattern adapts in a specific way as the stress is repeated (Chen \& Herbert, 1995; Stamp \& Herbert, 1999). 'Late' response genes are also altered by stress; for example, the expression of hypothalamic corticotrophin releasing factor (CRF) is increased by acute stress, and that of vasopressin by chronic stress (Ma \& Lightman, 1998). These peptides are behaviourally active (e.g. they increase anxiety-like states). Corticoids may alter the stress-dependent expression of some immediate-early genes (e.g. Fos-B) as well as of CRF and vasopressin. The relevance of these experimental findings to human psychiatric illness has yet to be adequately defined.

This selected review has suggested criteria to be used in human psychoendocrine studies; many of the studies discussed fall short of these standards. Hippocampal-hypothalamic-pituitary-adrenal axis function shows marked individual differences and these are likely to have both physiological and pathological significance, although the origins of the variations in circulating levels are not known. Events during either prenatal or early postnatal development may influence subsequent corticoid levels (cortisol and DHEA). The brain is sensitive to excess exposure to cortisol, with potential impairments in mental and behavioural function. The focus on cortisol as the only steroid of importance is too narrow, as both DHEA and gonadal steroids exert effects on behaviour during development and may influence the risk for and the maintenance of major depression in young people; its role in other psychopathologies is potentially intriguing but is yet to be adequately defined.

\section{ACKNOWLEDGEMENTS}

I.M.G. and J.H. are supported by the Wellcome Trust. This review was completed within the MRC Cooperative in Brain, Behaviour and Neuropsychiatry.

\section{APPENDIX}

\section{Proposed protocol for psycho-} endocrine studies in young people

I. Salivary collections taken at $08.00,12.00,16.00$ and $20.00 \mathrm{~h}$

2. Samples collected over at least four consecutive days.

3. Consider negative chemical implications of using salivary aids to salivation.

4. Validated assays to a research standard (sensitivity, accuracy, specificity)

5. Sufficient power (sample size) to avoid type ॥ errors.

6. Control and comparison groups appropriate to the research hypothesis.

7. Careful choice of derived measure for analysis (means, peaks, diurnal variation, ratios, etc.).

8. Monitor potential confounds, e.g. steroid therapies including inhalers, prescribed and illicit drugs.

9. Record lifestyle factors including exercise, dieting and smoking. 
10. Data analytic procedures should take into account gender differences, multiple or repeated comparisons.

\section{REFERENCES}

Altman, J. \& Das, G. D. (1965) Autoradiographic and histological evidence of postnatal hippocampal neurogenesis in rats. Journal of Comprehensive Neurology 124, 319-335.

Angold, A., Costello, E. J., Erkanl, A., et al (1999) Pubertal changes in hormone levels and depression in girls. Psychological Medicine, 29, I043-1053.

Anisman, H., Zahoria, M., Meaney, M. J., et al (1998) Do early life events permanently alter behavioural and emotional response to stressors? International journal of Developmental Neuroscience, 16, 149-164.

Anker, S. D., Clark, A. L., Kemp, M., et al (1997) Tumor necrosis factor and steroid metabolism in chronic heart failure: possible relation to muscle wasting. Journal of the American College of Cardiology, 30, 997-100I.

Baulieu, E. E. (1998) Neurosteroids: a novel function of the brain. Psychoneuroendocrinology, 23, 963-987.

Bender, B. G., Lerner, J. A. \& Kollasch, E. (1988) Mood and memory changes in asthmatic children receiving corticosteroids. Journal of the American Academy of Child and Adolescent Psychiatry, 27, 720-725.

Birmaher, B., Ryan, N. D., Dahl, R., et al (1992) Dexamethasone suppression test in children with majo depressive disorder. Journal of the American Academy of Child and Adolescent Psychiatry, 31, 291-297.

—, Dahl, R. E., Perel, J., et al (1996) Corticotropinreleasing hormone challenge in prepubertal major depression. Biological Psychiatry, 39, 267-277.

Blauer, K. L., Poth, M., Rogers, W. M., et al (1991) Dehydroepiandrosterone antagonizes the suppressive effects of dexamethasone on lymphocyte proliferation. Endocrinology, 129, 3174-3179.

Brittlebank, A. D., Scott, J., Williams, J. M. G., et al (1993) Autobiographical memory in depression: state or trait marker? British Journal of Psychiatry, 162, |18-121.

Brooks-Gunn, J., Petersen, A. C. \& Compas, B. (1995) Physiological processes and the development of childhood and adolescent depression. In The Depressed Child and Adolescent: Developmental and Clinical Perspectives (ed. I. M. Goodyer), pp. 8I-III. Cambridge: Cambridge University Press.

Buchanan, C., Eccles, J. \& Becker, J. (1992) Are adolescents victims of raging hormones: evidence for activational effects of hormones on moods and behaviour at adolescence. Psychological Bulletin, III, 62-107.

Cameron, H. A., Tanapat, P. \& Gould, E. (1998) Adrenal steroids and $\mathrm{N}$-methyl-D-aspartate recepto activation regulate neurogenesis in the dentate gyrus of adult rats through a common pathway. Neuroscience, 82, 349-354.

Chen, X. \& Herbert, J. (1995) Regional changes in $c$-fos expression in the basal forebrain and brainstem during adaptation to repeated stress: correlations with cardiovascular, hypothermic and endocrine responses. Neuroscience, 64, 675-685.

Cowen, P. J. (1998) Back to the future: the neurobiology of major depression. Psychological Medicine, 28, 253-255.

Dahl, R. E., Kaufman, J., Ryan, N. D., et al (1992) The dexamethasone suppression test in children and adolescents: a review and a controlled study. Biological Psychiatry, 32, 109-126.
De Bellis, M. D., Baum, A. S., Birmaher, B., et a (1999) A. E. Bennett Research Award. Developmental traumatology. Part I: Biological stress systems. Biological Psychiatry, 45, 1259-1270.

Eriksson, P. S., Perfilieva, E., Bjork-Eriksson, T., et a (1998) Neurogenesis in the adult human hippocampus. Nature Medicine, 4, 1313-1317.

Evans, R. M. \& Arriza, J. L. (1989) A molecular framework for the actions of glucocorticoid hormones in the nervous system. Neuron, 2, II05-1II2.

Gathercole, S. E. (1998) The development of memory Journal of Child Psychology and Psychiatry, 39, 3-27.

Goodyer, I. M., Herbert, J., Altham, P. M. E., et a (1996) Adrenal secretion during major depression in 8 to 16 year olds, l: Altered diurnal rhythms in salivary cortisol and dehydroepiandrosterone (DHEA) at presentation. Psychological Medicine, 26, 245-256.

_, _ , Secher, S., et al (1997a) Short term outcome of major depression: I. Comorbidity and severity at presentation as predictors of persistent disorder. Journal of the American Academy of Child and Adolescent Psychiatry, 36, 179-187.

_, _ \& Altham, P. M. E. (1997b) Short term outcome of major depression: III. A high cortisol/DHEA ratio and subsequent disappointing life events predict persistent depression. Psychological Medicine, 28, 265-273.

_, _ , Tamplin, A., et al (2000a) Recent life events, cortisol, dehydroepiandrosterone and the onset of major depression in high-risk adolescents. British Journal of Psychiatry, I77, 499-504.

_, _, _, et al (2000b) First-episode major depression in adolescents. Affective, cognitive and endocrine characteristics of risk status and predictors of onset. British Journal of Psychiatry, 176, 142-149.

Graeff, F. G., Guimaraes, F. S., De Andrade, T. G., et al (1996) Role of 5-HT in stress, anxiety, and depression. Pharmacology, Biochemistry and Behaviour, 54, 129-14|.

Granger, D. A., Weisz, J. R., McCracken, J.T., et al (1996) Reciprocal influences among adrenocortical activation, psychosocial processes, and the behavioral adjustment of clinic-referred children. Child

Development, 67, 3250-3262.

Guazzo, E. P., Kirkpatrick, P. J., Goodyer, I. M., et al (1996) Cortisol, dehydroepandrosterone (DHEA), and DHEA sulfate in the cerebrospinal fluid of man: relation to blood levels and the effects of age. Journal of Clinical Endocrinology and Metabolism, 81, 395I-3960.

Gunnar, M. R. (1998) Quality of early care and buffering of neuroendocrine stress reactions: potential effects on the developing human brain. Preventative Medicine, 27, 208-2II.

_ \& Nelson, C. A. (1994) Event-related potentials in year-old infants: relations with emotionality and cortisol. Child Development, 65, 80-94.

_ , Brodersen, L., Nachmias, M., et al (1996a) Stress reactivity and attachment security. Developmental Psychobiology, 29, |91-204.

_ , _ , Krueger, K., et al (1996b) Dampening of adrenocortical responses during infancy: normative changes and individual differences. Child Development, 67, 877-889.

— , Tout, K., de Haan, M., et al (1997) Temperament, social competence, and adrenocortical activity in preschoolers. Developmental Psychobiology, 3I, 65-85.

Harley, K. \& Reese, E. (1999) Origins of autobiographical memory. Developmental Psychology, 35, 1338-1348.
Herbert, J. (1997) Stress, the brain and mental illness. British Medical Journal, 315, 530-535.

, Martenz, N., Umberkomain-Wiita, B., et a (1982) Distribution of prolactin and cortisol between serum and CSF in rhesus monkeys. Frontiers of Hormone Research, 9, 159-172.

_ , Goodyer, I. M., Altham, P. M. E., et al (1996) Adrenal secretion and major depression in 8 to 16 year olds, II. Influence of co-morbidity at presentation. Psychological Medicine, 26, 257-263.

Holmes, M. C., French, K. L. \& Seckl, J. R. (1995) Modulation of serotonin and corticosteroid receptor gene expression in the rat hippocampus with circadian rhythm and stress. Brain Research and Molecular Brain Research, 28, 186-192.

Hortnagl, H., Berger, M. L., Havelec, L., et al (1993) Role of glucocorticoids in the cholinergic degeneration in rat hippocampus induced by ethylcholine aziridinium (AF64A). Journal of Neuroscience, 13, 2939-2945.

Irwin, R. P., Maragakis, N. J., Rogawski, M. A., et al (1992) Pregnenolone sulfate augments NMDA receptor mediated increases in intracellular $\mathrm{Ca} 2+$ in cultured rat hippocampal neurons. Neuroscience Letters, I4I, 30-34.

Kaplan, S. J., Pelcovitz, D. \& Labruna, V. (1999) Child and adolescent abuse and neglect research: a review of the past 10 years. Part I: Physical and emotional abuse and neglect. Journal of the American Academy of Child and Adolescent Psychiatry, 38, 1214-1222.

Kaufman, J., Birmaher, B., Perel, J., et al (1997) The corticotropin-releasing hormone challenge in depressed abused, depressed nonabused, and normal control children. Biological Psychiatry, 42, 669-679.

Keenan, P. A., Jacobson, M. W., Soleymani, R. M. et al (1996) The effect on memory of chronic prednisone treatment in patients with systemic disease. Neurology, 47, 1396-1402.

Kimonides, V. G., Spillantini, M. G., Sofroniew, M. V., et al (1999) Dehydroepiandrosterone antagonizes the neurotoxic effects of corticosterone and translocation of stress-activated protein kinase 3 in hippocampal primary cultures. Neuroscience, 89, 429-436.

Kirschbaum, C. \& Hellhammer, D. (1994) Salivary cortisol in psychoendocrine research: recent developments and applications. Psychoneuroendocrinology, 19, 313-333.

Kroboth, P. D., Salek, F. S., Pittenger, A. L., et al (1999) DHEA and DHEA-S: a review. Journal of Clinical Pharmacology, 39, 327-348.

Labrie, F., Belanger, A., Cusan, L., et al (1997) Marked decline in serum concentrations of adrenal $\mathrm{Cl} 9$ sex steroid precursors and conjugated androgen metabolites during aging. Journal of Clinical Endocrinology and Metabolism, 82, 2396-2402.

Lephart, E. D., Baxter, C. R. \& Parker, C. R. (1987) Effect of burn trauma on adrenal and testicular steroid hormone production. Journal of Clinical Endocrinology and Metabolism, 64, 842-848.

Lewis, M. \& Ramsay, D. (1995) Developmental change in infant's response to stress. Child Development, $6 \mathbf{6}$ 657-670.

Linkowski, P., Van Onderbergen, A., Kerkhofs, M., et al (1993) Twin study of the 24-h cortisol profile: evidence for genetic control of the human circadian clock. American Journal of Physiology, 264, El73-El8I.

Lupien, S. J., de Leon, M., de Santi, S., et al (1998) Cortisol levels during human aging predict hippocampa atrophy and memory deficits. Nature Neuroscience, 69-73. 
Lynch, M. \& Cicchetti, D. (1998) Trauma, mental representation, and the organization of memory for mother-referent material. Developmental Psychopathology, 10, 739-759.

Ma, X. M. \& Lightman, S. L. (1998) The arginine vasopressin and corticotrophin-releasing hormone gene transcription responses to varied frequencies of repeated stress in rats. Journal of Physiology (Lond.), $510,605-614$

McAllister-Williams, R. H., Ferrrier, I. N. \& Young, A. H. (1998) Mood and neuropsychological function in depression: the role of corticosteroids and serotonin. Psychological Medicine, 28, 573-584.

McBurnett, K., Lahey, B. B., Rathouz, P. J., et al (2000) Low salivary cortisol and persistent aggression in boys referred for disruptive behavior. Archives of General Psychiatry, 57, 38-43.

McEwen, B. S. \& Alves, S. E. (1999) Estrogen actions in the central nervous system. Endocrine Reviews, 20, 279-307.

Magarinos, A. M. \& McEwen, B. S. (1995) Stressinduced atrophy of apical dendrites of hippocampal $\mathrm{CA} 3 \mathrm{c}$ neurons: involvement of glucocorticoid secretion and excitatory amino acid receptors. Neuroscience, $\mathbf{6 9}$, 89-98.

Mao, X. \& Barger, S.W. (1998) Neuroprotection by dehydroepiandrosterone-sulfate: role of an NFkappaBlike factor. Neuroreport, 9, 759-763.

Meaney, M. J., Aitken, D. H., Viau, V., et al (1989) Neonatal handling alters adrenocortical negative feedback sensitivity and hippocampal type II glucocorticoid receptor binding in the rat. Neuroendocrinology, 50, 597-604.

Meikle, A. W., Stringham, J. D., Woodward, M. G. et al (1988) Heritability of variation of plasma cortisol levels. Metabolism, 37, 514-517.

Mishkin, M., Suzuki, W. A., Gadian, D. G., et al (1997) Hierarchical organization of cognitive memory. Philosophical Transactions of the Royal Society of London, Series B, Biological Sciences, 352, 1461-1467.

Moss, H. B., Vanyukov, M. M. \& Martin, C. S. (1995) Salivary cortisol responses and the risk for substance abuse in prepubertal boys. Biological Psychiatry, 38, 547-555.

Newcomer, J. W., Selke, G., Melson, A. K., et al (1999) Decreased memory performance in healthy humans induced by stress-level cortisol treatment. Archives of General Psychiatry, 56, 527-533.

Ohashi, M., Kato, K., Nawata, H., et al (1986) Adrenocortical responsiveness to graded ACTH infusions in normal young and elderly human subjects. Gerontology, 32, 43-5।

Park, S. B., Williamson, D. J. \& Cowen, P. J. (1996) 5-HT neuroendocrine function in major depression: prolactin and cortisol responses to D-fenfluramine. Psychological Medicine, 26, |191-1196.

Plotsky, P. M., Owens, M. J. \& Nemeroff, C. B. (1998) Psychoneuroendocrinology of depression. Hypothalamic-pituitary-adrenal axis. Psychiatric Clinics of North America, 2I, 293-307.

Pollak, S., Cicchetti, D. \& Klorman, R. (1998) Stress, memory, and emotion: developmental consideration from the study of child maltreatment. Development and Psychopathology, 10, 811-828.

Ramboz, S., Oosting, R., Amara, D., et al (1998) Serotonin receptor IA knockout: an animal model of

\section{CLINICAL IMPLICATIONS}

- Abnormalities in the human hypothalamic-pituitary-adrenal axis precede and contribute to the onset of major depression.

- High levels of corticoids may damage the brain and impair cognitive performance.

- The exact clinical effects of high levels of corticoids on neural systems and their related cognitive processes remain unclear.

\section{LIMITATIONS}

- The origins of individual differences in adrenal steroid levels remain unknown.

- It is not known whether the association between cortisol hypersecretion and difficult behaviour in young children is predictive of later psychopathology.

- The narrow focus on cortisol prevents firm conclusions being drawn about the interrelations of different steroids in behavioural development and the onset of subsequent psychopathology.

I. M. GOODYER, FRCPsych, R. J. PARK, MRCPsych, Developmental Psychiatry Section, Department of Psychiatry; C. M. NETHERTON, PhD, J. HERBERT, PhD, Department of Anatomy, University of Cambridge, UK

Correspondence: Dr I. M. Goodyer, Developmental Psychiatry Section, Department of Psychiatry, Cambridge University Clinical School, Douglas House, I8bTrumpington Road, Cambridge CB2 2AH, UK

(First received I February 2000, final revision 6 November 2000, accepted 6 November 2000)

anxiety-related disorder. Proceedings of the National Academy of Sciences of the United States of America, 95, |4476-|448|.

Rao, U., Dahl, R. E., Ryan, N. D., et al (1996) The relationship between longitudinal clinical course and sleep and cortisol changes in adolescent depression. Biological Psychiatry, 40, 474-484.

Rosenfeld, R. S., Hellman, L., Roffwarg, H., et al (197I) Dehydroisoandrosterone is secreted episodically and synchronously with cortisol by normal man. Journa of Clinical Endocrinology and Metabolism, 33, 87-92.

_ , Rosenberg, B. J., Fukushima, D. K., et al (1975) 24-hour secretory pattern of dehydroisoandrosterone and dehydroisoandrosterone sulfate. Journal of Clinical Endocrinology and Metabolism, 40, 850-855.

Sapolsky, R. M. (1996) Why stress is bad for your brain Science, 273, 749-750.

Schwartz, E. B., Granger, D. A., Susman, E. J., et al (1998) Assessing salivary cortisol in studies of child development. Child Development, 69, 1503-1513.

Schwarzschild, M. A., Cole, R. L. \& Hyman, S. E. (1997) Glutamate, but not dopamine, stimulates stress-activated protein kinase and AP-I-mediated transcription in striatal neurons. Journal of Neuroscience, I7, 3455-3466.

Stamp, J. A. \& Herbert, J. (1999) Multiple immediateearly gene expression during physiological and endocrine adaptation to repeated stress. Neuroscience, 94, $1313-1322$

Susman, E. J., Dorn, L. D. \& Chrousos, G. P. (199I) Negative affect and hormone levels in young adolescents: concurrent and predictive perspectives. Journal of Youth and Adolescence, 20, 167-190.

Taylor, A., Fisk, N. \& Glover, V. (2000) Mode of delivery and subsequent stress response. Lancet, 355, 120 .

Van Goozen, S., Matthys, W., Cohen-Kettenis, P. et al (1998a) Salivary cortisol and cardiovascular activity during stress in oppositional-defiant disorder boys and normal controls. Biological Psychiatry, 43, 53I-539.

_ , _ , _ , et al (1998b) Adrenal androgens and aggression in conduct disorder prepubertal boys and normal controls. Biological Psychiatry 43, 156-158.

, _ _, et al (2000) Hypothalamic-pituitaryadrenal axis and autonomic nervous system activity in disruptive children and matched controls. Journal of The American Academy of Child Adolescent Psychiatry, 39, 1438-1445.

Vazquez, D. M. (1998) Stress and the developing limbic-hypothalamic-pituitary-adrenal axis. Psychoneuroendocrinology, 23, 663-700.

Westphal, U. (1970) Binding of hormones to serum proteins. In Biochemical Actions of Hormones (ed. G. Litwack), Vol. I, pp. 209-265. New York: Academic Press. 